\title{
PROFESSORES INICIANTES: UM PANORAMA DAS INVESTIGAÇÕES BRASILEIRAS
}

\author{
BEGINNING TEACHERS: A VIEW OF BRAZILIAN TEACHERS \\ PROFESORES PRINCIPIANTES: UN PANORAMA DE LAS \\ INVESTIGACIONES BRASILEÑAS
}

\author{
Silmara de Oliveira Gomes Papi ${ }^{*}$ \\ Camila Boczkoski Carvalho**
}

\begin{abstract}
Resumo: Segundo Marcelo (1999), o período de entrada na profissão, quando o professor é considerado iniciante, é um período relevante para a docência. Os desafios - e, muitas vezes, as dificuldades que o professor vivencia nessa etapa são tema de muitos estudos, que destacam, ainda, o impacto desse período na aprendizagem profissional. As investigações sobre professores iniciantes têm sido intensificadas no Brasil, e as diferentes constatações têm suscitado novas reflexões e demandas. Este estudo buscou analisar quais são as tendências das pesquisas brasileiras sobre professores iniciantes apresentadas em um Congresso Internacional cuja proposta voltou-se à divulgação das investigações sobre essa temática. O estudo foi desenvolvido na perspectiva de um estado do conhecimento tal como proposto por Romanowski e Ens (2006), e buscou analisar os focos de estudo, resultados e metodologias das diferentes pesquisas. Concluiu-se que a maioria das pesquisas analisadas é voltada à investigação do professor iniciante na Educação Básica, mas também se observaram pesquisas sobre o iniciante na Educação Superior. As análises demonstram que aspectos relacionados às dificuldades ou dilemas enfrentados por esses professores encontram-se em evidência tanto nos focos de estudo quanto nos resultados apresentados pelas pesquisas, sobrepondo-se a estudos interventivos em relação a esse período (ainda que os estudos interventivos estejam em ascensão no Brasil). Esse aspecto pode indicar um avanço em relação à formação de professores nessa etapa profissional inicial.
\end{abstract}

Palavras-chave: Formação de professores. Professor iniciante. Inserção profissional.

Abstract: According to Marcelo (1999), the initial period of the profession, when the teacher is considered a beginner, it relevant to teaching. The challenges - and often the difficulties - that the teacher faces in this stage are the subject of many studies, which also highlight the impact of this period in professional learning. In Brazil, researches on new teachers are intensified, and its results have sparked new ideas and demands. This study aimed to examine which are the trends of the Brazilian researches on beginning teachers presented at an international congress whose proposal was to disseminate researches on this topic. The study was conducted from the perspective of a state of knowledge as proposed by Romanowski and Ens (2006), and aimed to examine focus of study, results and methodologies of different researches. It concluded that most researches are focused on the study of new teachers in Basic Education, but also found researches on new teachers in Higher

\footnotetext{
* Doutora em Educação pela Pontifícia Universidade Católica do Paraná. Professora adjunta da Universidade Estadual de Ponta Grossa - UEPG, Departamento de Educação. Correio eletrônico: silmarapapi@terra.com.br.

** Graduada em Pedagogia pela Universidade Estadual de Ponta Grossa - UEPG (2012). Correio eletrônico: camilaboczkoski@yahoo.com.br.
} 
Education. Analyses demonstrate that aspects related to difficulties or dilemmas faced by these teachers are evidenced both as study focuses as on results presented by the researches, overlapping interventional studies related to that period (although interventional studies are a trend in Brazil). This aspect indicates an evolution in relation to teacher training in this early stage of their career.

Keywords: Teacher training. Beginning teachers. Employability.

Resumen: Según Marcelo (1999), el periodo de entrada en la profesión, cuando se considera al profesor un principiante, es un período relevante para la docencia. Los retos -y, muchas veces, las dificultadescon los que el profesor se enfrenta en esta etapa son tema de muchos estudios, que subrayan, además, el impacto de este periodo en el aprendizaje profesional. Las investigaciones sobre profesores principiantes se han intensificado en Brasil, y tales constataciones han suscitado nuevas reflexiones y demandas. Este estudio buscó analizar cuáles son las tendencias de las investigaciones brasileñas acerca de profesores principiantes presentadas en un Congreso Internacional cuya propuesta estuvo dirigida hacia la divulgación de las investigaciones sobre esta temática. El estudio fue desarrollado en la perspectiva de un estado del conocimiento tal como propuesto por Romanowski y Ens (2006), y buscó analizar los focos de estudio, resultados y metodologías de las distintas investigaciones. Se concluye que la mayoría de las investigaciones analizadas está dirigida hacia la investigación del profesor principiante en la Educación Básica, pero también se observaron investigaciones sobre el principiante en la Educación Superior. Los análisis demuestran que los aspectos asociados a las dificultades o dilemas con los que se enfrentan estos profesores se encuentran en evidencia tanto en los focos de estudio como en los resultados presentados por las investigaciones, sobreponiéndose a estudios intervencionales acerca de este período (aunque los estudios intervencionales estén en ascensión en Brasil). Este aspecto señala un avance en relación a la formación de los profesores en esta etapa profesional inicial.

Palabras clave: Formación de profesores. Profesor principiante. Inserción profesional.

\section{Introdução}

O processo de formação docente constitui-se de fases ou etapas diferenciadas. Ele se inicia formalmente com a chamada etapa de formação inicial, que prepara o professor para o exercício da profissão, prolongando-se na formação continuada, que ocorre durante o período em que o professor já exerce a profissão. Por esse motivo, Marcelo (1999) considera tal formação como um processo contínuo.

Durante essa trajetória, há um período compreendido como um dos responsáveis pela permanência na profissão e pela sedimentação das bases para o exercício profissional. Essa fase é denominada "período de iniciação docente”, e, de acordo com Papi e Martins (2010), é de grande importância para o para o professor.
Marcelo (1999) afirma que o período de iniciação é constituído pela passagem do professor da condição de aluno para a condição de profissional. Essa fase pode ser caracterizada por dilemas e dificuldades (MARCELO, 1999; MARCELO; VAILLANT, 2009), o que se deve ao choque com as condições de trabalho e com a cultura da instituição escolar, e ainda ao envolvimento do novo docente com os membros do grupo profissional. Esse envolvimento representa a inserção e a socialização do docente iniciante nesse grupo.

É necessário compreender os estudos acerca de tal problemática, pois a melhoria das condições vivenciadas pelos professores iniciantes passa pelo entendimento de como esse campo de estudo tem sido desenvolvido, ressaltando-se as conquistas efetivadas 
e as permanências e empecilhos que ainda podem ser predominantes na prática.

O presente trabalho tem como objetivo explicitar as tendências das pesquisas brasileiras sobre professores iniciantes apresentadas no III Congreso Internacional sobre Profesorado Principiante e Inserción Profesional a la Docencia - Santiago do Chile, realizado de 29 de fevereiro a 2 de março de 2012. Tais pesquisas indicam um panorama, ainda que amplo, da investigação sobre o tema no Brasil, bem como da realidade vivida por professores que se encontram nessa etapa da carreira.

Após a presente introdução, apresentam-se algumas considerações sobre o período de iniciação à docência. Em seguida, destaca-se a metodologia utilizada para o desenvolvimento da investigação. Prosseguindo, o texto traz a análise dos dados coletados, finalizando com algumas considerações sobre os resultados obtidos.

\section{A participação da pesquisa brasileira no III Congreso Internacional sobre Profesorado Principiante e Inserción Profesional a la Docencia}

Um aspecto relevante para a profissão docente, bem como a para formação e o desenvolvimento profissional do professor, é a pesquisa voltada a essas áreas e os diferentes enfoques e possibilidades que apresenta, pois, a partir de seus resultados, essa pesquisa pode contribuir significativamente para os avanços pretendidos e para a superação das dificuldades da profissão.

Atualmente as pesquisas sobre formação de professores possuem múltiplos focos, e, segundo Papi e Martins (2010), isso ocorre devido às necessidades presentes em relação ao âmbito educativo neste momento histórico. As pesquisas enfatizam diferentes assuntos relativos à área, mas ainda são relativamente recentes os estudos que se voltam à análise do professor e de sua formação no período de iniciação profissional, que corresponde à fase da entrada do docente na profissão (PAPI; MARTINS, 2010). Esse período é caracterizado por marcas próprias, como o sentimento de sobrevivência, a fase de descoberta e o choque com o real (HUBERMAN, 1995).

Conforme Huberman (1995), o sentimento de sobrevivência é desencadeado a partir do choque com o real, pois muitas vezes o que foi idealizado durante a formação inicial entra em conflito com a realidade existente na escola. A fase de descoberta caracteriza-se pelo maior ânimo do professor, pois ele se sente motivado pelo pertencimento a um grupo profissional, bem como por ter os próprios alunos e uma sala de aula para gerir.

Em seu período de iniciação, o professor pode vivenciar situações mais ou menos difíceis, dependendo das características do profissional e do espaço escolar em que ele está inserido (PAPI; MARTINS, 2010). Segundo Lima (2006), um dos aspectos que podem se configurar como uma dificuldade para o docente no início da profissão é o sentimento de solidão, muitas vezes desencadeado pela ausência de auxílio ao seu trabalho por parte da equipe coordenadora e dos demais professores da instituição escolar. Outro elemento complicador citado pela autora é o tipo de participação da família ou dos pais na escola, e, consequentemente, na aprendizagem dos alunos.

Considerando tais aspectos, foram abordadas as pesquisas brasileiras que, a partir de diferentes enfoques, dedicam-se ao estudo do professor iniciante, procurando-se, com isso, compreender os diferentes focos de estudo e os resultados capazes de estabelecer uma aproximação com o panorama da investigação sobre a temática. 


\section{Aspectos metodológicos do estudo}

Para a efetivação deste estudo, considerou-se o III Congreso Internacional sobre Profesorado Principiante e Inserción Profesional a la Docencia. O evento teve como proposta tornar-se um “[...] espaço de encontro, reflexão e intercâmbio entre investigadores, formadores e docentes preocupados com a formação dos professores que começam a ensinar. " Foi organizado pelo grupo espanhol de investigação "IDEA!", formado por professores da Universidade de Sevilha e da Universidade de Huelva.

Desenvolveu-se um estudo no âmbito de um estado do conhecimento tal como proposto por Romanowski e Ens (2006), ou seja, fez-se um levantamento sobre as publicações relativas a um assunto específico, mas sem a pretensão de esgotar os diversos espaços de socialização acadêmica possíveis - o que faz com que este estudo se diferencie de uma pesquisa do tipo estado da arte. Segundo Romanowski e Ens (2006), a pesquisa do tipo estado da arte mapeia toda uma área do conhecimento, destacando o que está sendo apresentado ou abordado nessa área, ressaltando as contribuições das pesquisas e também suas principais limitações.

O estudo é de caráter qualitativo - embora alguns dados quantitativos tenham sido considerados - e teve como fonte as comunicações (foram desconsiderados as mesas-redondas, as conferências e os simpósios) apresentadas no Congresso observado e disponibilizadas nos anais do evento. De acordo com o material, foram apresentados um total de 133 trabalhos - na forma de comunicações e originários de dez países diferentes.

Para a realização do estudo, foram seguidos os seguintes passos:

1. Disponível em: <http://prometeo.us.es/congreso/index.htm>. Acesso em: 5 ago. 2013. a) Consulta aos anais do evento disponibilizados em CD-ROM como fonte principal de coleta de dados, bem como à sua página on-line para esclarecimentos sobre o evento;

b) Classificação dos artigos disponíveis no CD-ROM por país de origem e seleção das comunicações de autores(as) brasileiros(as);

c) Construção de um quadro a partir da localização, nos trabalhos dos pesquisadores brasileiros, de dados referentes ao foco de estudo, ao nível de ensino privilegiado, aos aspectos metodológicos e aos principais resultados apontados, a fim de verificar as tendências dessas pesquisas;

d) Análise dos dados levantados, tendo em vista as pesquisas sobre professores iniciantes.

Segundo a proposta apresentada pelo Congresso, observa-se que se trata de um evento preocupado com a qualidade do ensino, a prática do professor iniciante e com sua formação e seu desenvolvimento profissional.

\section{O que evidenciam os dados}

Em relação à primeira etapa realizada, isto é, a verificação do País de origem das comunicações apresentadas no evento, foram constatados dez países participantes, sendo: Angola (1), Argentina (21), Brasil (76), Canadá (1), Chile (9), Colômbia (3), Espanha (1), México (16), Portugal (1) e Uruguai (4).

No mapeamento constata-se que, no âmbito dos países envolvidos, o Brasil foi o que teve o maior número de participações, somando um total de 76 Comunicações (57,1\% do total). Isso pode significar um 
processo crescente de interesse dos pesquisadores brasileiros em divulgar seus trabalhos em nível internacional, possibilitando a ampliação da visão externa acerca do que vem sendo pesquisado no país. Pode indicar também um interesse crescente pela temática.

Em relação à segunda etapa do estudo, que diz respeito à Análise das tendências das pesquisas apresentadas pelos pesquisadores brasileiros, construiu-se, para facilitar a compreensão dos dados, um quadro a partir da localização, nos artigos disponíveis, dos seguintes aspectos: título da comunicação, nível de ensino privilegiado, aspectos metodológicos, temática abordada/foco da pesquisa, principais resultados.

Em decorrência da organização e da análise desse quadro, verificou-se que, do total de 76 trabalhos divulgados, 44 (33\% do total), diziam respeito especificamente ao tema "professores iniciantes". 32 tratavam de temas correlatos, abordando aspectos como a formação inicial (vinculada à prática de ensino e ao estágio, à relação teoria-prática, a partir de programas formativos articulados com a formação inicial, ao contexto histórico da formação de docentes e à inserção da mulher na profissão, aos processos de avaliação do desenvolvimento profissional do professor - não especificamente iniciante - e à discussão sobre a escolha da profissão), a prática de professores da Educação Básica a partir da educação inaciana e da teoria complexidade e o perfil dos docentes da Academia da Força Aérea, além de haver uma abordagem sobre o Curso Bilíngue de Pedagogia na América Latina.

Nesse sentido, considerando-se que o objeto de estudo deste trabalho são as pesquisas que tratam de professores iniciantes, somente os 44 trabalhos diretamente ligados ao tema foram analisados.
No conjunto desses trabalhos, observou-se que trinta deles referem-se ao período de iniciação docente em relação à Educação Básica, e, outros doze, à Educação Superior, evidenciando que nesse evento, houve maior dedicação dos pesquisadores aos estudos sobre professores iniciantes vinculados à Educação Básica. Os dois últimos trabalhos que compõem esse grupo foram desenvolvidos com base em mapeamentos, deixando de referir-se especificamente a um ou outro nível de ensino.

\section{Abordagem metodológica das pesquisas}

No que diz respeito aos aspectos metodológicos presentes nos trabalhos brasileiros apresentados no Congresso, em sentido amplo, vê-se que tanto as pesquisas voltadas à Educação Básica quanto aquelas voltadas à Educação Superior utilizam, em sua quase totalidade, a abordagem qualitativa de pesquisa, com exceção de uma delas (referente à Educação Básica) que aponta utilizar os "pressupostos das pesquisas qualitativas e quantitativas" (LEIRIAS; FERNANDES, 2012, p.1). Para isso, desenvolvem seus estudos a partir de pesquisa-formação, estudos de caso, estudo exploratório, pesquisa narrativa, entre outras metodologias, conforme se pode observar:

Com o intuito de melhor compreender os dilemas pelos quais os docentes se deparam no início da carreira, desenvolvemos uma pesquisa qualitativa do tipo estudo de caso [...]. (ILHA; KRUG, 2012, p.1).

Quanto à metodologia, trata-se de uma pesquisa-formação cujos participantes são ao mesmo tempo sujeitos da pesquisa e formam-se com/nela [...]. (NOGUEIRA; MELIN; ALMEIDA, 2012, p.2).

A metodologia seguiu o modelo de pesquisa qualitativa, do tipo exploratória, [...] (RIBEIRO, 2012, p.1). 
[...] estamos desenvolvendo uma investigação qualitativa de cunho narrativo, [...]. (BARBIERO et al., 2012, p.4)

Em relação às duas comunicações que realizaram mapeamentos, apresentadas por Cunha e Cunha, (2012) e Costa, Voltarelli e Cunha (2012), ambas evidenciam o tipo de pesquisa utilizada. A primeira é apontada como um estudo dos trabalhos apresentados no II Congreso Internacional sobre Profesorado Principiante. Na segunda comunicação, o tipo de pesquisa explicitado pelas autoras é um estado do conhecimento, que objetivou analisar o que revelam as publicações (teses e dissertações) sobre professores iniciantes no programa de pós-graduação em Educação da UFSCar no período de 2000 a 2010.

A partir desse levantamento inicial sobre o tipo de pesquisa realizada, pode-se constatar que as pesquisas sobre professores iniciantes, especificamente no caso deste trabalho (III Congresso de Professores Iniciantes), apresentam o predomínio do caráter qualitativo. Isso permite traçar uma comparação entre esse dado e a pesquisa elaborada por Papi e Martins (2009), que teve como objetivo realizar um levantamento sobre as abordagens metodológicas das pesquisas referentes ao tema professores iniciantes dos "trabalhos apresentados nas Reuniões da Anped realizadas nos anos de 2005, 2006 e 2007, nos GTs 04, 08 e 14" (PAPI; MARTINS, 2009, p.251). As autoras apontam que a maioria dos trabalhos analisados realizou um estudo qualitativo, como indicado pelo presente estudo.

Em relação aos instrumentos de coleta de dados utilizados nas pesquisas, expressos nos textos das comunicações analisadas, observou-se um predomínio da utilização de entrevistas e questionários semiestruturados, análise documental, observação, narrativas, e técnica de grupo focal, como se verifica nos excertos a seguir:
[...]. Trata-se, portanto, de pesquisa empírica, de natureza qualitativa, cuja metodologia incluiu o uso de questionários e entrevistas semiestruturadas para coleta dos dados [...]. (FURLAN, 2012, p.2).

[...]. Utilizamos as seguintes técnicas [...]: a entrevista semiestruturada, a observação não participante e a análise documental. [...] (MIRANDA, 2012, p.1).

Tendo em vista o propósito de investigar os desafios colocados a professoras [...] no Ensino Fundamental, optou-se por utilizar, no âmbito das abordagens qualitativas, a técnica do grupo focal. (AMBROSETTI; ALMEIDA; CALIL, 2012, p.4).

[...] os instrumentos serão questionários semiestruturados, entrevistas semiestruturas individuais e coletivas (conforme andamento da pesquisa), análise documental, [...]. (SILVEIRA; FERNANDES; SILVA, 2012, p.1).

Em termos gerais, constatou-se que o instrumento de coletas de dados mais utilizado nos trabalhos foi a entrevista semiestruturada, seguida pelas narrativas e questionários. Em relação à utilização de narrativas, verifica-se a presença significativa desse instrumento, confirmando o que foi ressaltado por Papi e Martins (2009), que afirmam ter havido um crescimento da utilização desse recurso metodológico nas pesquisas sobre professores iniciantes.

\section{Foco de estudo das pesquisas}

Em relação aos focos de estudo das pesquisas sobre professores iniciantes apresentadas no congresso, observou-se a existência de convergências entre os múltiplos interesses privilegiados verificados após a análise dos trabalhos nos dois grupos (Educação Básica e Educação Superior), tendo sido especialmente observados os títulos, problemas e objetivos. 
Quadro 1. Foco de estudo dos trabalhos referentes à Educação Básica

\begin{tabular}{|c|c|c|}
\hline Identificação da pesquisa & Foco de estudo & $\begin{array}{l}\text { Número de } \\
\text { pesquisas }\end{array}$ \\
\hline $\begin{array}{l}\text { Lisboa et al. (2012); Evangelista (2012); Bragança e Oliveira (2012); Gari- } \\
\text { glio et al. (2012); Corrêa e Antunes (2012); Freitas e Ramos (2012). }\end{array}$ & $\begin{array}{l}\text { Descrição da traje- } \\
\text { tória do período de } \\
\text { inserção docente. }\end{array}$ & 6 \\
\hline Reali, Tancredi e Mizukami (2012); Dal-Forno (2012) & $\begin{array}{l}\text { Experiências de } \\
\text { programas on-line }\end{array}$ & 2 \\
\hline $\begin{array}{l}\text { Calil; Ambrosetti e Almeida (2012); Papi (2012); Pilz e Pinto (2012); Ilha } \\
\text { e Krug (2012); Ilha e Krug (2012); Cardoso e Nunes (2012); Ambrosetti, } \\
\text { Almeida e Calil (2012). }\end{array}$ & $\begin{array}{l}\text { Desafios/dilemas/ } \\
\text { dificuldades no início } \\
\text { da carreira. }\end{array}$ & 7 \\
\hline Leirias e Fernandes (2012); Nogueira, Melin e Almeida (2012). & $\begin{array}{l}\text { Acompanhamento } \\
\text { pedagógico (pelo } \\
\text { supervisor, pesquisa- } \\
\text {-formação) ao profes- } \\
\text { sor iniciante. }\end{array}$ & 2 \\
\hline Romanowski e Martins (2012). & $\begin{array}{l}\text { Elementos da organi- } \\
\text { zação do trabalho do } \\
\text { professor iniciante. }\end{array}$ & 1 \\
\hline $\begin{array}{l}\text { Cartaxo e Machado (2012); Cruz, Andréa e Passos (2012); Martins (2012); } \\
\text { Simon e Fernandes (2012). }\end{array}$ & $\begin{array}{l}\text { Contribuições da for- } \\
\text { mação inicial para o } \\
\text { período de inserção. }\end{array}$ & 4 \\
\hline André (2012); Portella (2012). & $\begin{array}{l}\text { Programas e políticas } \\
\text { de apoio aos profes- } \\
\text { sores iniciantes. }\end{array}$ & 2 \\
\hline Furlan (2012); Gabardo e Hobold (2012). & $\begin{array}{l}\text { Processo de sociali- } \\
\text { zação do docente. }\end{array}$ & 2 \\
\hline Cerezer e Guimarães (2012). & $\begin{array}{l}\text { Saberes e práticas de } \\
\text { professores iniciantes. }\end{array}$ & 1 \\
\hline Silveira, Fernandes e Silva (2012); Oliveira (2012). & $\begin{array}{l}\text { Narrativas dos pro- } \\
\text { fessores iniciantes. }\end{array}$ & 2 \\
\hline Brostolin (2012). & $\begin{array}{l}\text { Ser e estar na pro- } \\
\text { fissão. }\end{array}$ & 1 \\
\hline
\end{tabular}

Fonte: Organizado pelas autoras, com base nos anais do evento.

Assim, no caso das trinta pesquisas sobre professores iniciantes da Educação Básica, percebeu-se que um número maior de pesquisas investiga desafios, dilemas ou dificuldades relacionadas ao período de iniciação, bem como busca compreender a trajetória vivida pelo professor nesse período. Um número menor de trabalhos destaca, na perspectiva do iniciante, aspectos como elementos da organização do trabalho pedagógico de professores iniciantes, saberes e práticas desses professores e o ser e estar na profissão docente, conforme se observa no Quadro 1.

No que se refere aos trabalhos voltados à Educação Superior, foram encontradas 
Quadro 2. Foco de estudo dos trabalhos referentes à Educação Superior.

\begin{tabular}{l|l|c}
\hline Identificação da pesquisa & Foco de estudo & $\begin{array}{c}\text { Número de } \\
\text { pesquisas }\end{array}$ \\
\hline Ribeiro (2012) & Construção da aula universitária & 1 \\
\hline $\begin{array}{l}\text { Barbiero et al. (2012); Ferreira (2012); Zanchet et al. } \\
\text { (2012); Borges, Hunder e Rodrigues (2012); Miranda } \\
\text { (2012) }\end{array}$ & $\begin{array}{l}\text { Desafios vivenciados por professores } \\
\text { iniciantes }\end{array}$ & 5 \\
\hline $\begin{array}{l}\text { Luz, Mello e Broilo (2012; Stivanin e Zanchet (2012); } \\
\text { Becker Vighi et al. (2012) }\end{array}$ & $\begin{array}{l}\text { Programas de apoio aos professores } \\
\text { iniciantes }\end{array}$ & 3 \\
\hline $\begin{array}{l}\text { Ribeiro, Feldkercher e Souza (2012) } \\
\text { Nascimento (2012); Feldkercher, Ribeiro e Souza } \\
\text { (2012) }\end{array}$ & $\begin{array}{l}\text { Perspectivas do professor iniciante sobre a } \\
\text { qualidade da Educação Superior }\end{array}$ & 1 \\
\hline
\end{tabular}

Fonte: Organizado pelas autoras, com base nos anais do evento.

doze pesquisas. Constatou-se que a maioria desses trabalhos interessa-se pelos desafios pelos quais passam os professores iniciantes. Em seguida, vêm as investigações relacionadas a programas de apoio a professores iniciantes, de acordo com o que se observa no Quadro 2.

Com base no levantamento realizado, é possível afirmar que a maioria das pesquisas brasileiras desenvolvidas no âmbito da Educação Básica e no da Educação Superior interessa-se pelos principais desafios/dilemas desse período inicial da profissão. Segundo Marcelo (1999), o enfoque nas dificuldades dos professores iniciantes indica o que caracteriza esse momento profissional, o que pode ser associado ao sentimento de sobrevivência apontado por Huberman (1995) em seus estudos.

Além desse dado, destacam-se também nos dois grupos as discussões em torno da socialização do professor iniciante. Sobre esse aspecto, Freitas (2002, p.156) alerta que "para a compreensão do processo de socialização profissional, é necessário levar em conta tanto a história do professor iniciante, suas expectativas e projetos, quanto as características do grupo profissional a que irá pertencer".
Outro aspecto presente nos dois grupos de pesquisas é o interesse por programas de apoio aos professores iniciantes, seja o estudo de um programa de residência docente para professores em início de carreira na Educação Básica (PORTELLA, 2012), a análise de programas para professores universitários (LUZ; MELLO; BROILO, 2012; STIVANIN; ZANCHET, 2012; BECKER VIGHI et al, 2012), ou um estudo que procura responder à questão: "E no Brasil, existem políticas voltadas aos professores iniciantes?” (ANDRÉ, 2012, p.4). Nesse estudo, apontam-se iniciativas pontuais específicas para professores iniciantes, destacadas como promissoras, e que se efetivam em duas Secretarias Municipais: no município de Sobral, Estado Ceará, e no município de Campo Grande, Estado do Mato Grosso do Sul.

Na perspectiva de Carter e Richardson (1989 apud MARCELO, 1999, p.119):

Os programas de iniciação, tal como qualquer outra atividade de formação de professores, incluem, [...] três componentes fundamentais: um conceito de ensino e formação; uma seleção do conhecimento que considera adequado e necessário ao 
professor principiante; e, por último, uma ideia de como se adquire esse conhecimento, ou seja, as estratégias formativas que facilitam a sua aquisição [...].

De acordo com Marcelo (1998 apud MARCELO, 1999), os programas de apoio à inserção profissional docente têm como principal finalidade facilitar esse processo de entrada no ambiente escolar, ou, como o próprio autor menciona, "na cultura institucional”. É uma ação importante, diante das dificuldades que o profissional iniciante encontra nos primeiros anos de atuação.

Em relação às pesquisas no âmbito de mapeamentos, desenvolvidas por Cunha e Cunha (2012), e, ainda, por Costa, Voltarelli e Cunha (2012), constatou-se um foco diferenciado: a primeira propôs-se a analisar as produções científicas apresentadas na edição anterior do evento aqui observado, enquanto a segunda destacou a análise das produções relacionadas a um programa de pós-graduação, como se apresenta a seguir:

[...] este estudo que tomou os trabalhos apresentados no II Congresso Internacional sobre Professorado Principiante realizado em Buenos Aires, em 2010, para analisar temas e tendências que vêm marcando a pauta de discussão sobre tão importante tema. [...] (CUNHA; CUNHA, 2012, p.1).

O presente estudo tem como temática central a análise das produções científicas, mais especificamente das dissertações e teses, defendidas no Programa de Pós-Graduação em Educação (PPGE doravante) da Universidade Federal de São Carlos (UFSCar) na linha de "Formação de Professores e outros agentes educacionais" no período de 2000 a 2010. (COSTA; VOLTARELLI; CUNHA, 2012, p.1).

Apesar de cada pesquisa ter investigado um espaço diferente, ambas pretendem analisar as publicações sobre o tema professores iniciantes e, consequentemente, como essas publicações estão abordando essa fase do profissional docente.

\section{Resultados destacados nas pesquisas}

A análise dos resultados obtidos a partir dos dados coletados foi realizada especialmente (não exclusivamente) com base nas "Considerações finais" presentes nos artigos, embora, em muitos casos, quando esse item do trabalho não apresentou dados suficientes, buscou-se localizar mais elementos no corpo do artigo. Os dados foram dispostos no quadro de análise e, posteriormente, foram também observados em relação à sua recorrência. Respostas semelhantes foram agrupadas.

Com base nessa organização, obtiveram-se resultados que se apresentam da seguinte forma, em relação à Educação Básica:

a) dez pesquisas ressaltam os dilemas/ dificuldades vividos no período de iniciação profissional;

b) nove pesquisas apontam o período de iniciação como um desafio;

c) seis pesquisas destacam que há ausência de auxílio/orientação da escola (professores, funcionários, gestores) ao professor iniciante;

d) sete pesquisas apresentam como importantes os saberes das formações inicial e continuada para o professor iniciante;

e) quatro pesquisas ressaltam a importância das políticas e programas de assessoramento ao docente iniciante;

f) quatro pesquisas afirmam a ausência de políticas de acompanhamento ao professor iniciante; 
g) quatro pesquisas salientam a importância da participação/auxílio da equipe gestora;

h) três pesquisas indicam que o processo de socialização na carreira ocorreu de forma positiva;

i) duas pesquisas destacam a fragilidade na formação inicial e a ausência de vivências práticas pelos futuros professores;

j) duas pesquisas ressaltam que os professores principiantes buscaram relacionar teoria e prática na ação educativa;

k) duas pesquisas destacam que os professores iniciantes, ao se inserirem na escola, começam a aprender aspectos da cultura dessa instituição;

l) uma pesquisa ressalta a necessidade de melhores condições de trabalho;

m) uma pesquisa destaca que os professores iniciantes estabelecem concepções antecipadas sobre a prática profissional;

n) uma pesquisa aponta a existência de programas de apoio para a inserção profissional (parceria universidade-escola);

o) uma pesquisa ressalta os primeiros anos como decisivos ao docente iniciante;

p) uma pesquisa salienta a ausência de tempo para o professor iniciante estudar;

q) uma pesquisa indica que o processo de formação de professoras mentoras iniciantes é complexo;

r) uma pesquisa não apresenta resultados, pois está em fase inicial.

Nas pesquisas sobre o professor iniciante na Educação Básica, vê-se a quantidade expressiva de trabalhos que evidenciam que o período de iniciação é relacionado por muitos professores principiantes à vivência de dilemas ou dificuldades. Pode-se ressaltar que os principais dilemas dessa fase de inserção profissional mencionados foram o choque com a realidade, a insegurança, as turmas com grande número de alunos, a sobrevivência, sendo que um dos artigos apontou esse período como assustador (FREITAS; RAMOS, 2012). Os resultados correspondem à análise de Huberman (1995) referente ao período de iniciação docente, pois retratam que o confronto inicial com a realidade escolar gera dificuldades para o docente iniciante.

Outro aspecto relativo à Educação Básica é a ausência de auxílio da escola a esse profissional, bem como a escassez de políticas de acompanhamento ao professor iniciante, tal como apresenta Marcelo (1999). Para o autor, esses programas podem promover uma assessoria ao docente em sua prática inicial, contribuindo para a inserção do profissional iniciante.

Por meio desse levantamento, verificou-se também a importância dos conhecimentos construídos na formação inicial para a atuação profissional do docente. De acordo com Imbernón (2011, p.60) a formação inicial "deve fornecer as bases para construir esse conhecimento pedagógico especializado". O autor afirma que um dos objetivos da formação inicial é trabalhar uma abordagem científica consistente para a formação docente.

Nos dados que se referem à Educação Superior, constatam-se alguns resultados diferenciados e outros semelhantes aos apresentados pelos trabalhos que trataram do professor iniciante na Educação Básica. Com referência a esse nível de ensino, verifica-se que:

a) quatro pesquisas destacam que há dificuldades no período de iniciação docente; 
b) duas pesquisas destacam a importância do acolhimento dos membros da instituição para a atuação do profissional iniciante;

c) duas pesquisas ressaltam que os programas de inserção facilitam o processo adaptativo do docente iniciante;

d) duas pesquisas apresentam o período de iniciação como um momento de aprendizagem;

e) duas pesquisas apontam que a qualidade para a atuação docente envolve o professor, o aluno e a infraestrutura da instituição;

f) uma pesquisa destaca que professores da graduação são tidos como exemplos para a atuação do professor iniciante na Educação Superior;

g) uma pesquisa chama a atenção para a relevância de alguns projetos de acompanhamento ao docente iniciante;

h) uma pesquisa ressalta a importância dos diários como fonte de pesquisa sobre o cotidiano do professor principiante;

i) duas pesquisas ressaltam a importância da formação em nível de pós-graduação para a atuação do professor principiante na Educação Superior;

j) uma pesquisa demonstra que as políticas de inserção se encontram em nível inicial;

k) uma pesquisa apontou o início de carreira como uma fase de constituição da docência;

l) uma pesquisa destaca a ausência de programas de acompanhamento ao professor iniciante.

Assim como apontam os dados referentes à Educação Básica, na Educação Superior os desafios/dificuldades aparecem em destaque. As dificuldades retratadas nas pesquisas têm relação com a insegurança e o choque com a realidade nessa fase de inserção profissional, como se verifica no trabalho apresentado por Miranda (2012, p.7): "[...] entre os três professores participantes foi Vicenzo quem mais sentiu o choque com a realidade. Para ele, o início de carreira foi uma fase bastante difícil de superar. Relatou ter sentido insegurança nas primeiras experiências com o magistério [...]."

Tal como indicado por Marcelo (1999), outro fator levantado pelas pesquisas referentes à Educação Superior e à Educação Básica é a importância das políticas/programas de assessoramento ao docente iniciante:

O acolhimento em programas de inserção e redes tende a facilitar o processo adaptativo dos professores ingressantes no contexto da docência. No entanto não é esta ainda a realidade existente em nosso contexto de estudo. [...]. (BARBIERO et al, 2012, p.8).

Entendemos que não se pode trabalhar com o professor iniciante do mesmo modo que aquele que já possui uma vasta experiência ou conhecimento da instituição, pois as necessidades são diferentes [...]. (LUZ; MELLO; BROILO, 2012, p.4)

Além dos aspectos indicados, verifica-se, em duas pesquisas, a importância da formação na pós-graduação para o docente da Educação Superior, em especial em relação à formação pedagógica:

Agora reconhecem que a universidade lhes projetou possibilidades e isso é muito gratificante, o que lhes motiva a estudarem para dar uma boa aula, mesmo reconhecendo as sérias limitações impostas pela ausência de cursos de pós-graduação - mais da metade dos participantes têm apenas a graduação (RIBEIRO, 2012, p.7). 
Os professores reafirmaram que para o exercício da docência no ensino superior, a formação de sua base profissional é importante mesmo que não ela não seja voltada para o ensino. No entanto, mostraram preocupação em relação à formação pedagógica [...] (ZANCHET et al., 2012, p.6).

Constata-se que as dificuldades que os docentes principiantes vivenciam constituem o principal aspecto de análise nas pesquisas do III Congresso de Professores Iniciantes, apresentando-se, também, como relevante no âmbito dos resultados elencados.

Três constatações diferenciadas do que se nota no âmbito da Educação Básica chamam a atenção: a constatação do papel dos professores da graduação como modelos para os iniciantes na Educação Superior; a constatação de que a qualidade do Ensino Superior envolve o professor, o aluno e a infraestrutura existente; e, ainda, a importância da formação em nível de pós-graduação para os professores da Educação Superior.

Em relação às duas pesquisas do tipo "levantamento", de Cunha e Cunha (2012) e de Costa, Voltarelli e Cunha (2012), ambas tinham como proposta efetivar um mapeamento acerca das reflexões das pesquisas sobre professores principiantes.

A pesquisa de Cunha e Cunha (2012, p.1), intitulada "O campo de conhecimento e as práticas sobre a iniciação à docência: o que revela a produção científica no II Congresso Internacional sobre Professorado Principiante”, destaca como resultados das pesquisas analisadas a dicotomia entre teoria e prática na formação inicial e o foco na identidade profissional do professor no período de iniciação. Realça ainda os estudos sobre as "metodologias investigativas como favorecedoras de processos de intervenção na educação dos professores iniciantes" (CUNHA; CUNHA, 2012, p.5), como é apresentado a seguir:
Chama a atenção o impacto desses estudos, evidenciando que as propostas de formação inicial vivem uma permanente tensão entre os polos da teoria e da prática e do ensino e da pesquisa. [...]. (CUNHA; CUNHA, 2012, p.3).

O conceito de identidade profissional é recorrente nos trabalhos apresentados e indica a busca de um princípio organizativo da vida dos professores (CUNHA; CUNHA, 2012, p.4).

[...] foram onze os trabalhos que tiveram como eixo principal a iniciação à docência e a pesquisa. Reunimos [...] as produções que exploravam metodologias investigativas como favorecedoras de processos de intervenção na educação dos professores iniciantes (CUNHA; CUNHA, 2012, p.5).

A segunda pesquisa (COSTA; VOLTARELLI; CUNHA, 2012) tem como título "Pesquisas sobre professores iniciantes: o estado de conhecimento no programa de pós-graduação em Educação UFSCar 2000-2010”. O trabalho das autoras focou a atenção em um programa de pós-graduação e evidencia as seguintes considerações:

[...] podemos perceber, além de um forte interesse dos pesquisadores pelos professores dos primeiros anos do Ensino Fundamental, um olhar mais interessado pelas dificuldades enfrentadas nesse período [...]. (COSTA; VOLTARELLI; CUNHA, 2012, p.4-5).

Na totalidade dos textos, fica claro que o professor iniciante vivencia o "choque de realidade”, [...]. (COSTA; VOLTARELLI; CUNHA, 2012, p.5).

[...] os trabalhos de Migliorança (2010) e Pieri (2010) destacam [...] aspectos positivos para o desenvolvimento profissional docente quando há um acompanhamento desses professores devido, principalmente, no que tange os conflitos vivenciados nesse período. [...]. (COSTA; VOLTARELLI; CUNHA, 2012, p.6) 
Costa, Voltarelli e Cunha (2012) apontam o interesse das pesquisas pelas dificuldades enfrentadas pelo professor iniciante, mas indicam também pesquisas que apontam a importância de acompanhamento específico a esse professor - ou de políticas de assessoramento, tal como foi destacado em outras pesquisas aqui analisadas e que focaram a Educação Básica e a Educação Superior. Essas convergências reafirmam a necessidade se considerar mais enfaticamente esses aspectos.

\section{Para concluir}

Este estudo buscou compreender as tendências das pesquisas brasileiras apresentadas na modalidade "Comunicação", no III Congresso Internacional sobre Professores Iniciantes, realizado em Santiago do Chile em 2012. Refletiu-se sobre as abordagens das pesquisas voltadas ao período de iniciação docente. As análises demonstram que aspectos relacionados às dificuldades ou dilemas enfrentados por esses professores encontram-se em evidência tanto nos focos de estudo quanto nos resultados apresentados pelas pesquisas, sobrepondo-se a estudos interventivos em relação a esse período, ainda que esses demonstrem estar em ascensão no Brasil. Isso pode ser indicativo de um avanço em relação à formação de professores nessa etapa profissional.

Destacou-se no congresso a participação quantitativamente superior $(57,1 \%)$ das pesquisas brasileiras - em relação à de outros países participantes.

Dos 44 trabalhos selecionados - por serem especificamente sobre professores iniciantes -, mais da metade aborda o período de iniciação em relação a professores da Educação Básica, sendo que um número menor enfatiza a Educação Superior. Porém, muitos resultados mostram convergências em relação aos dois níveis de educação, apontando a identificação de dificuldades no início da carreira por parte de professores desses dois níveis de ensino, constituindo e/ ou confirmando, assim, um dos aspectos de caracterização dessa fase inicial da carreira docente já destacada por diferentes autores.

Também se evidencia nos trabalhos a quase ausência de políticas e programas de assessoramento ao profissional docente em início de carreira, o que retrata a forma como as instâncias superiores concebem o período de iniciação docente, deixando de atribuir-lhe a importância necessária - embora sejam apontadas experiências pontuais de assessoramento.

Além disso, destaca-se nas investigações que o período inicial da carreira é importante e decisivo para a constituição da identidade profissional docente e a consolidação na profissão, sendo que a construção de conhecimentos teórico-práticos na formação inicial e na formação continuada, embora indispensável para esse enfrentamento inicial, muitas vezes ainda representa um desafio.

Ressalta-se também que a equipe gestora da escola assume um papel fundamental nesse processo, assessorando a prática profissional do professor iniciante.

Assim, entende-se que, embora desafios sejam relativamente comuns diante de situações novas, a questão central no caso do professor iniciante é a intensidade que esses desafios podem assumir em seu trabalho, transformando-se muitas vezes em dificuldades. Daí vem sua necessidade de apoio institucional, cuja carência pode comprometer o processo de ensino-aprendizagem e a própria carreira do professor.

Esta pesquisa demonstra que as comunicações dos pesquisadores brasileiros 
apresentadas no III Congreso Internacional sobre Profesorado Principiante e Inserción Profesional a la Docencia mostram-se importantes para os estudos sobre o período de iniciação à docência e para a consolidação da investigação e da prática na área. Mas demonstra, também, que os dados evidenciados nos diferentes estudos analisados podem colaborar para que seja efetivado um novo encaminhamento para o período de inserção profissional, possibilitando ainda a compreensão da relação entre essa etapa profissional e a formação inicial e continuada do professor.

\section{Referências bibliográficas}

AMBROSETTI, N. B.; ALMEIDA, P. A.; CALIL, A. M. G. C. Ingresso profissional: o aprendizado da docência no espaço escolar. In: CONGRESO INTERNACIONAL SOBRE PROFESORADO PRINCIPIANTE E INSERCIÓN PROFESIONAL A LA DOCENCIA, 3., 2012, Santiago de Chile. Anais... Santiago de Chile: UA, 2012. 1 CD-ROM.

ANDRÉ, M. Políticas e programas de apoio aos professores iniciantes no Brasil. In: CONGRESO INTERNACIONAL SOBRE PROFESORADO PRINCIPIANTE E INSERCIÓN PROFESIONAL A LA DOCENCIA, 3., 2012, Santiago de Chile. Anais... Santiago de Chile: UA, 2012. 1 CD-ROM.

BARBIERO, D. R. et al. A inserção profissional na carreira docente enquanto movimento construtivo da docência na Educação Profissional Tecnológica. In: CONGRESO INTERNACIONAL SOBRE PROFESORADO PRINCIPIANTE E INSERCIÓN PROFESIONAL A LA DOCENCIA, 3., 2012, Santiago de Chile. Anais... Santiago de Chile: UA, 2012. 1 CD-ROM.

BECKER VIGHI, C. S. et al. Início da carreira universitária: alternativas de apoio apontadas por docentes iniciantes. In: CONGRESO INTERNACIONAL SOBRE PROFESORADO PRINCIPIANTE E INSERCIÓN PROFESIONAL A LA DOCENCIA, 3., 2012, Santiago de Chile. Anais... Santiago de Chile: UA, 2012. 1 CD-ROM.

BORGES, C.; HUNGER, D.; RODRIGUES, J. P. História de vida de um professor de Educação Física: contando e encantando. In: CONGRESO INTERNACIONAL SOBRE PROFESORADO PRINCIPIANTE E INSERCIÓN PROFESIONAL A LA DOCENCIA, 3., 2012, Santiago de Chile. Anais... Santiago de Chile: UA, 2012. 1 CD-ROM.

BRAGANÇA, I. F. S.; OLIVEIRA, M. S. Acompanhamento de professoras/es iniciantes: (com) partilhando uma experiência brasileira com egressos do curso de Pedagogia da UERJ. In: CONGRESO INTERNACIONAL SOBRE PROFESORADO PRINCIPIANTE E INSERCIÓN PROFESIONAL A LA DOCENCIA, 3., 2012, Santiago de Chile. Anais... Santiago de Chile: UA, 2012. 1 CD-ROM.

BROSTOLIN, M. R. Professor iniciante: o ser e estar na profissão docente. In: CONGRESO INTERNACIONAL SOBRE PROFESORADO PRINCIPIANTE E INSERCIÓN PROFESIONAL A LA DOCENCIA, 3., 2012, Santiago de Chile. Anais... Santiago de Chile: UA, 2012. 1 CD-ROM.

CALIL, A. M. G. C.; AMBROSETTI, N. B.; ALMEIDA, P. A. Desafios enfrentados no processo de iniciação à docência. In: CONGRESO INTERNACIONAL SOBRE PROFESORADO PRINCIPIANTE E INSERCIÓN PROFESIONAL A LA DOCENCIA, 3., 2012, Santiago de Chile. Anais... Santiago de Chile: UA, 2012. 1 CD-ROM.CARDOSO, S.; NUNES, C. Sentimentos e desafios de professores principiantes: construindo o habitus professoral. In: CONGRESO INTERNACIONAL SOBRE PROFESORADO 
PRINCIPIANTE E INSERCIÓN PROFESIONAL A LA DOCENCIA, 3., 2012, Santiago de Chile. Anais... Santiago de Chile: UA, 2012. 1 CD-ROM.

CARTAXO, S. R. M.; MACHADO, I. C. Professores iniciantes da Educação Infantil em processo de formação: um estudo de caso da relação teoria-prática. In: CONGRESO INTERNACIONAL SOBRE PROFESORADO PRINCIPIANTE E INSERCIÓN PROFESIONAL A LA DOCENCIA, 3., 2012, Santiago de Chile. Anais... Santiago de Chile: UA, 2012. 1 CD-ROM.

CEREZER, O. M.; GUIMARÃES, S. Professores de História principiantes e a implantação da Lei Federal que tornou obrigatório o estudo de História e da cultura Afro-brasileira e Indígena no Ensino Básico no Brasil. In: CONGRESO INTERNACIONAL SOBRE PROFESORADO PRINCIPIANTE E INSERCIÓN PROFESIONAL A LA DOCENCIA, 3., 2012, Santiago de Chile. Anais... Santiago de Chile: UA, 2012. 1 CD-ROM.

CORRÊA, P. M.; ANTUNES, A. L. O início da docência em uma escola privada de rede. In: CONGRESO INTERNACIONAL SOBRE PROFESORADO PRINCIPIANTE E INSERCIÓN PROFESIONAL A LA DOCENCIA, 3., 2012, Santiago de Chile. Anais... Santiago de Chile: UA, 2012. 1 CD-ROM.

COSTA, C. S; VOLTARELLI, M. A.; CUNHA, R. C. Pesquisas sobre professores iniciantes: o estado do conhecimento no programa de pós-graduação em Educação UFSCar 2000-2010. In: CONGRESO INTERNACIONAL SOBRE PROFESORADO PRINCIPIANTE E INSERCIÓN PROFESIONAL A LA DOCENCIA, 3., 2012, Santiago de Chile. Anais... Santiago de Chile: UA, 2012. 1 CD-ROM.

CRUZ, G. B.; ANDRÉ, M.; PASSOS, L. F. O papel das práticas de Licenciatura no desenvolvimento profissional de professores em início de carreira. In: CONGRESO INTERNACIONAL SOBRE PROFESORADO PRINCIPIANTE E INSERCIÓN PROFESIONAL A LA DOCENCIA, 3., 2012, Santiago de Chile. Anais... Santiago de Chile: UA, 2012. 1 CD-ROM.

CUNHA, M. I.; CUNHA, C. M. O campo de conhecimento e as práticas sobre a iniciação à docência: o que revela a produção científica no II Congresso Internacional sobre Professorado Principiante. In: CONGRESO INTERNACIONAL SOBRE PROFESORADO PRINCIPIANTE E INSERCIÓN PROFESIONAL A LA DOCENCIA, 3., 2012, Santiago de Chile. Anais... Santiago de Chile: UA, 2012. 1 CD-ROM.

DAL-FORNO, J. P. Contribuições de um programa online para formação de professores da Educação Básica. In: CONGRESO INTERNACIONAL SOBRE PROFESORADO PRINCIPIANTE E INSERCIÓN PROFESIONAL A LA DOCENCIA, 3., 2012, Santiago de Chile. Anais... Santiago de Chile: UA, 2012. 1 CD-ROM.

EVANGELISTA, E. G. A inserção na docência de professores que atuam como formadores de Língua Portuguesa. In: CONGRESO INTERNACIONAL SOBRE PROFESORADO PRINCIPIANTE E INSERCIÓN PROFESIONAL A LA DOCENCIA, 3., 2012, Santiago de Chile. Anais... Santiago de Chile: UA, 2012. 1 CD-ROM.

FELDKERCHER, N.; RIBEIRO, G. M.; SOUZA, H. B. M. Relações entre professores iniciantes e estudantes: elementos do processo de socialização profissional docente. In: CONGRESO INTERNACIONAL SOBRE PROFESORADO PRINCIPIANTE E INSERCIÓN PROFESIONAL A LA DOCENCIA, 3., 2012, Santiago de Chile. Anais... Santiago de Chile: UA, 2012. 1 CD-ROM. 
FERREIRA, L. A. O início da carreira docente na Educação Física: um olhar a partir dos diários. In: CONGRESO INTERNACIONAL SOBRE PROFESORADO PRINCIPIANTE E INSERCIÓN PROFESIONAL A LA DOCENCIA, 3., 2012, Santiago de Chile. Anais... Santiago de Chile: UA, 2012. 1 CD-ROM.

FREITAS, J. T.; RAMOS, G. N. S. Opiniões de professores de Educação Física em início de carreira docente. In: CONGRESO INTERNACIONAL SOBRE PROFESORADO PRINCIPIANTE E INSERCIÓN PROFESIONAL A LA DOCENCIA, 3., 2012, Santiago de Chile. Anais... Santiago de Chile: UA, 2012. 1 CD-ROM.

FREITAS, M. N. C. Organização escolar e socialização profissional de professores iniciantes. Cadernos de Pesquisa, n. 115, p.155-172, mar. 2002. Disponível em: $<$ http://www.scielo.br/pdf/cp/n115/a06n115. pdf>. Acesso em: 6 ago. 2013.

FURLAN, E. G. M. Processos de socialização profissional de professores iniciantes de Química. In: CONGRESO INTERNACIONAL SOBRE PROFESORADO PRINCIPIANTE E INSERCIÓN PROFESIONAL A LA DOCENCIA, 3., 2012, Santiago de Chile. Anais... Santiago de Chile: UA, 2012. 1 CD-ROM.

GABARDO, C. V.; HOBOLD, M. S. O processo de socialização profissional dos professores do Ensino Fundamental. In: CONGRESO INTERNACIONAL SOBRE PROFESORADO PRINCIPIANTE E INSERCIÓN PROFESIONAL A LA DOCENCIA, 3., 2012, Santiago de Chile. Anais... Santiago de Chile: UA, 2012. 1 CD-ROM.

GARIGLIO, J. Â. et al. Professores de Educação Física e a entrada na profissão docente: uma iniciação a docência singular? In: CONGRESO INTERNACIONAL SOBRE PROFESORADO PRINCIPIANTE E IN-
SERCIÓN PROFESIONAL A LA DOCENCIA, 3., 2012, Santiago de Chile. Anais... Santiago de Chile: UA, 2012. 1 CD-ROM.

HUBERMAN, M. O ciclo de vida profissional dos professores. In: NÓVOA, A. Vidas de professores. Porto: Porto Editora, 1995.

ILHA, F. R. S.; KRUG, H. N. Os dilemas da docência de professores iniciantes de Educação Física Escolar. In: CONGRESO INTERNACIONAL SOBRE PROFESORADO PRINCIPIANTE E INSERCIÓN PROFESIONAL A LA DOCENCIA, 3., 2012, Santiago de Chile. Anais... Santiago de Chile: UA, 2012. 1 CD-ROM.

Os professores iniciantes e a gestão dos dilemas na Educação Física Escolar. In: CONGRESO INTERNACIONAL SOBRE PROFESORADO PRINCIPIANTE E INSERCIÓN PROFESIONAL A LA DOCENCIA, 3., 2012, Santiago de Chile. Anais... Santiago de Chile: UA, 2012. 1 CD-ROM.

IMBERNÓN, F. Formação docente e profissional: formar-se para a mudança e a incerteza. 9. ed. São Paulo: Cortez, 2011.

LEIRIAS, C. M.; FERNANDES, C. M. B. Desenvolvimento profissional de professores iniciantes: reflexões acerca da ação supervisora. In: CONGRESO INTERNACIONAL SOBRE PROFESORADO PRINCIPIANTE E INSERCIÓN PROFESIONAL A LA DOCENCIA, 3., 2012, Santiago de Chile. Anais... Santiago de Chile: UA, 2012. 1 CD-ROM.

LIMA, E. F. Sobre(as)vivências no início da docência: que recados elas nos deixam? In: LIMA, E. F. (Org.). Sobrevivências no início da docência. Brasília: Líber Livro, 2006. p.91-100.

LISBOA, W. J. et al. A inserção de professores de creches no município de Cuiabá, Mato Grosso - Brasil. In: CONGRESO INTERNACIONAL SOBRE 
PROFESORADO PRINCIPIANTE E INSERCIÓN PROFESIONAL A LA DOCENCIA, 3., 2012, Santiago de Chile. Anais... Santiago de Chile: UA, 2012. 1 CD-ROM.

LUZ, A. S.; MELLO, E. M. B.; BROILO, C. L. Desenvolvimento profissional e o professor ingressante na universidade. In: CONGRESO INTERNACIONAL SOBRE PROFESORADO PRINCIPIANTE E INSERCIÓN PROFESIONAL A LA DOCENCIA, 3., 2012, Santiago de Chile. Anais... Santiago de Chile: UA, 2012. 1 CD-ROM.

MARCELO, C. Formação de professores: Para uma mudança educativa. Porto: Porto Editora. 1999.

MARCELO, C.; VAILLANT, D. Desarrollo profesional docente: $\dot{c}$ como se aprende a ensinar? Madrid: Narcea, 2009.

MARTINS, F. P. Professores iniciantes: desafios da profissão docente. In: CONGRESO INTERNACIONAL SOBRE PROFESORADO PRINCIPIANTE E INSERCIÓN PROFESIONAL A LA DOCENCIA, 3., 2012, Santiago de Chile. Anais... Santiago de Chile: UA, 2012. 1 CD-ROM.

MIRANDA, S. O percurso profissional de três professores universitários de Educação Física no início da carreira. In: CONGRESO INTERNACIONAL SOBRE PROFESORADO PRINCIPIANTE E INSERCIÓN PROFESIONAL A LA DOCENCIA, 3., 2012, Santiago de Chile. Anais... Santiago de Chile: UA, 2012. 1 CD-ROM.

NASCIMENTO, M. G. C. A. Professores formadores e o processo de socialização profissional docente. In: CONGRESO INTERNACIONAL SOBRE PROFESORADO PRINCIPIANTE E INSERCIÓN PROFESIONAL A LA DOCENCIA, 3., 2012, Santiago de Chile. Anais... Santiago de Chile: UA, 2012. 1 CD-ROM.
NOGUEIRA, E. G. D; MELIN, A. P. G; ALMEIDA, O. A. Diálogos e acompanhamento: os professores iniciantes e suas práticas em questão. In: CONGRESO INTERNACIONAL SOBRE PROFESORADO PRINCIPIANTE E INSERCIÓN PROFESIONAL A LA DOCENCIA, 3., 2012, Santiago de Chile. Anais... Santiago de Chile: UA, 2012. 1 CD-ROM.

OLIVEIRA, R. M. M. A. Professores iniciantes, experientes e pesquisadores em grupo colaborativo: narrativas de formação. In: CONGRESO INTERNACIONAL SOBRE PROFESORADO PRINCIPIANTE E INSERCIÓN PROFESIONAL A LA DOCENCIA, 3., 2012, Santiago de Chile. Anais... Santiago de Chile: UA, 2012. 1 CD-ROM.

PAPI, S. O. G. Os desafios vivenciados por professoras iniciantes em seu processo de desenvolvimento profissional. In: CONGRESO INTERNACIONAL SOBRE PROFESORADO PRINCIPIANTE E INSERCIÓN PROFESIONAL A LA DOCENCIA, 3., 2012, Santiago de Chile. Anais... Santiago de Chile: UA, 2012. 1 CD-ROM.

PAPI, S. O. G.; MARTINS, P. L. O. As pesquisas sobre professores iniciantes: algumas aproximações. Educação em Revista, Belo Horizonte, v. 26, n. 03, p.39-56, dez. 2010.

Professores iniciantes: as pesquisas e suas bases teórico-metodológicas. Linhas Críticas, Brasília, v. 15, n. 29, p.251-269, jul./dez. 2009.

PILZ, C.; PINTO, N. B. Iniciação profissional de professores de Matemática: dificuldades e alternativas. In: CONGRESO INTERNACIONAL SOBRE PROFESORADO PRINCIPIANTE E INSERCIÓN PROFESIONAL A LA DOCENCIA, 3., 2012, Santiago de Chile. Anais... Santiago de Chile: UA, 2012. 1 CD-ROM.

PORTELLA, V. Residência docente: um programa em desenvolvimento. In: CONGRESO INTERNACIONAL SOBRE 
PROFESORADO PRINCIPIANTE E INSERCIÓN PROFESIONAL A LA DOCENCIA, 3., 2012, Santiago de Chile. Anais... Santiago de Chile: UA, 2012. 1 CD-ROM.

REALI, A. M. M. R.; TANCREDI, R. M. S. P; MIZUKAMI, M. G. Construção e desenvolvimento de uma comunidade de aprendizagem profissional de mentoras: tensões nos processos de desenvolvimento profissional. In: CONGRESO INTERNACIONAL SOBRE PROFESORADO PRINCIPIANTE E INSERCIÓN PROFESIONAL A LA DOCENCIA, 3., 2012, Santiago de Chile. Anais... Santiago de Chile: UA, 2012. 1 CD-ROM.

RIBEIRO, G. M.; FELDKERCHER, N; SOUZA, H. B. M. A qualidade da Educação Superior: tessituras a partir da perspectiva de docentes iniciantes. In: CONGRESO INTERNACIONAL SOBRE PROFESORADO PRINCIPIANTE E INSERCIÓN PROFESIONAL A LA DOCENCIA, 3., 2012, Santiago de Chile. Anais... Santiago de Chile: UA, 2012. 1 CD-ROM.

RIBEIRO, M. C. R. A construção da aula no Ensino Superior: concepções de professores iniciantes da Universidade do Piauí. In: CONGRESO INTERNACIONAL SOBRE PROFESORADO PRINCIPIANTE E INSERCIÓN PROFESIONAL A LA DOCENCIA, 3., 2012, Santiago de Chile. Anais... Santiago de Chile: UA, 2012. 1 CD-ROM.

ROMANOWSKI, J. P.; MARTINS, P. L. O. Elementos da organização do trabalho docente no desenvolvimento profissional de professores iniciantes. In: CONGRESO INTERNACIONAL SOBRE PROFESORADO PRINCIPIANTE E INSERCIÓN PROFESIONAL A LA DOCENCIA, 3., 2012, Santiago de Chile. Anais... Santiago de Chile: UA, 2012. 1 CD-ROM.

ROMANOWSKI, J. P; ENS, R. T. As pesquisas denominadas do tipo "Estado da Arte" em Educação. Revista Diálogo Educ., Curitiba, vol. 6, n.19, p.37-50, set./dez. 2006. Disponível em: <http://redalyc.uaemex.mx/ redalyc/pdf/1891/189116275004.pdf.>. Acesso em: 19 set. 2012.

SILVEIRA, D. N.; FERNANDES, C. M. B; SILVA, R. B. Professores principiantes: o que nos contam as narrativas dos egressos da Licenciatura de Matemática. In: CONGRESO INTERNACIONAL SOBRE PROFESORADO PRINCIPIANTE E INSERCIÓN PROFESIONAL A LA DOCENCIA, 3., 2012, Santiago de Chile. Anais... Santiago de Chile: UA, 2012. 1 CD-ROM.

SIMON, M. S.; FERNANDES, C. M. B. Professores iniciantes: teorias, práticas, dilemas e desafios. In: CONGRESO INTERNACIONAL SOBRE PROFESORADO PRINCIPIANTE E INSERCIÓN PROFESIONAL A LA DOCENCIA, 3., 2012, Santiago de Chile. Anais... Santiago de Chile: UA, 2012. 1 CD-ROM.

STIVANIN, N. F.; ZANCHET, B. M. B. A. Docentes universitários iniciantes: percepções sobre um programa de inserção à docência. In: CONGRESO INTERNACIONAL SOBRE PROFESORADO PRINCIPIANTE E INSERCIÓN PROFESIONAL A LA DOCENCIA, 3., 2012, Santiago de Chile. Anais... Santiago de Chile: UA, 2012. 1 CD-ROM.

ZANCHET, B. M. B. A. et al. Docentes universitários iniciantes: motivações, experiências iniciais e desafios. In: CONGRESO INTERNACIONAL SOBRE PROFESORADO PRINCIPIANTE E INSERCIÓN PROFESIONAL A LA DOCENCIA, 3., 2012, Santiago de Chile. Anais... Santiago de Chile: UA, 2012. 1 CD-ROM.

Enviado: 14/03/2013 Aceito em: 19/07/2013 